\title{
Report and evaluation of Brazilian experience in the rehabilitation of patients with leprosy
}

\author{
M VIRMOND*, F DUERKSEN† \& A GONÇALVES $\ddagger$ \\ * Health Department of RGS and Hospital 'Lauro de Souza Lima', \\ Brazil; Health Science Centre, Manitoba University, Canada; \\ $\ddagger$ Division of Dermatological Medicine, University of São Paulo, \\ Brazil
}

Accepted for publication 7 April 1989

\begin{abstract}
Summary As part of an investigation of the rehabilitation of physically disabled leprosy patients, a report and evaluation of Brazilian experience in this area is given.

After describing leprosy as a genuine and relevant public health problem in Brazil because of the numbers involved, the suffering caused and the difficulties inherent in its control the authors emphasize the important role of physical disability in this context. The description of a project set up in 1975 shows a model based on a Reference Centre as an epicentre for irradiating triggering action in five Brazilian cities. The results obtained thus far consist of 32 courses given at the Ref erence Centre and approximately 449 surgical interventions performed by one of the authors, $93 \cdot 10 \%$ of which were considered satisfactory.

The need to evaluate the clinical and therapeutic procedures involved from an epidemiological viewpoint is emphasized.
\end{abstract}

\section{Introduction}

The study by Gonçalves ${ }^{1}$ of leprosy as a public health problem in Brazil reveals a serious and important endemic disease both in absolute and relative terms. For example, Central America as a whole has the same number of officially registered cases as only a single neighbourhood in the city of Saõ Paulo. Andean America (Bolivia, Chile, Columbia, Ecuador, Peru and Venezuela) has a number of registered patients only a little higher than the number affected in only one of the 23 Brazilian states. In fact approximately $80 \%$ of all cases occur in Brazil.

With respect to the difficulties inherent in the control of the disease, Sansarricq ${ }^{2}$ has clearly stated that up to now the control of the disease has been directly related to individual care, while the impact of epidemiological measures depends primarily on the early diagnosis and adequate treatment of a large proportion of cases. However, the only detection method available is a clinical one and consequently it can only be applied by experienced professionals with specialized knowledge. Because of these difficulties, among many others, control programmes require complex and burdensome mechanisms involving organizational and logistic problems. These problems are 
further increased by the fact that regions where the disease is most prevalent are already burdened by other obvious and pressing health problems.

The suffering caused is related mainly to the deformities accompanying the evolution of the disease, which are variously identified as impairments, deficiencies and disabilities according to whether the viewpoint is that of the outside observer, the patient or society. ${ }^{3}$ Some clinical epidemiological studies have revealed surprising data. One study ${ }^{4}$ reported that the percentage of deformities is $35 \cdot 85 \%$ in Argentina, $48.7 \%$ in Burma, 35.6\% in the Cameroons, $23.4 \%$ in Nigeria, $32.22 \%$ in the Philippines and $41.46 \%$ in Thailand. In Brazil, one study ${ }^{5}$ showed a $75.3 \%$ prevalence of grade 1 disabilities, $27 \cdot 3 \%$ of grade 2 disabilities, and $4 \cdot 8 \%$ of grade 3 at a health service in the State of São Paulo (the criteria of degrees of disability is adapted from the OMS, 19836). In a study ${ }^{7}$ of 2080 patients from the State of Rio Grande do Sul, 68.7\% with some type of disability were detected, although the highest percentage (30.05\%) corresponded to grade 1 .

\section{Materials and method}

In view of the situation presented above, a project was started in 1975 for a more dynamic physical rehabilitation of leprosy patients. Joint efforts by the technical directorship of the 'Lauro de Souza Lima' Hospital of Bauru, SP, and by the president's office of the American Leprosy Missions, Inc., New Jersey, funded a visit to Brazil by one of the authors (FD), a surgeon specializing in the rehabilitation of leprosy patients. Starting from this visit and with the support of a Brazilian agency, the Evangelical Committee for the Rehabilitation of Patients with Hanseniasis (CERPHA), an ongoing programme of training and assistance for the rehabilitation of leprosy patients was instituted, with the 'Lauro de Souza Lima' Hospital serving as the central institution.

The main activities of the programme are concerned with the training of surgeons and technical medical personnel in rehabilitation procedures, so that these professionals will include patients with leprosy in their daily practice. Thus, we avoid the need to train someone to be a 'leprosy surgeon', i.e. a surgeon involved only with leprosy patients. In this way, plastic, orthopaedic and neurosurgeons (the main specialists involved with physical rehabilitation) will treat leprosy patients in their daily practice. The programme is also based on the local development of rehabilitation programmes using resources available in the community and integrated into the local leprosy control programme. For this purpose, once the location has been selected in terms of its epidemiological characteristics and by analysis of the technical staff available, the following procedures are implemented:

\section{Training of staff at the National Reference Centre}

In addition to being a Reference Centre for training, the 'Lauro de Souza Lima' Hospital acts as an integrated rehabilitation centre for the State of São Paulo, where all necessary facilities, surgery, physiotherapy, ortheses and prostheses, are available. The Hospital also co-operates with a nongovernmental agency, the Society for the Reintegration of the Disabled (SORRI), which acts mainly at the professional rehabilitation level. In view of the influence they exert on trainees, it should be emphasized that these two institutions are not limited to caring for leprosy patients, but also treat other types of disability.

\section{Activities of programme implantation}

These activities consist of on-site visits by specialists who select cases and operate in order to provide both patient care and teaching assistance to technical staff involved in the local programme as a continuation of the activities mentioned above.

The objectives of decentralization of patient care and removal of the stigma from the disease are 
achieved by relying on local community resources. Thus, general hospitals are used for surgery, physiotherapy centres provided by the National Health Insurance System are utilized, and even the services of commercial shoe stores are sought for the preparation of special shoes or simple modifications. In this manner, an attempt is made to render the patients less dependent on the specialized leprosy control service by stimulating their integration into the general network of health care.

\section{Activities of programme maintenance}

These consist of periodical supervisory visits for motivation and programme regulation.

From a methodological point of view, in addition to current plastic surgery practice for facial lesions, the following techniques have been used in a systematic and standardized manner:

Lagophthalmos: temporal temporalis muscle transfer (Gillis, ${ }^{8}$ and modified by Andersen ${ }^{9}$ ).

2 Claw hand: 'lasso' procedure of Zancolli ${ }^{10}$ and four tailed transfer of the superficialis tendon (Stilles-Bunnell ${ }^{11}$ ).

3 Lack of thumb opposition: ' $Y$ ' technique of Bunnell-Brand ${ }^{12}$ using the superficialis as motor.

4 Drop foot: transfer of the posterior tibial muscle with insertion into the tendons of the hallux extensor and into the common extensor of the toes. ${ }^{13}$

5 Clawed toes: transfer of the flexor to the extensor by the techniques of Girdlestone and Taylor. ${ }^{14}$

\section{Results}

TRAINING OF PERSONNEL

The continuity and impact of training activities at the Reference Centre may be appraised by considering that, with the completion of the latest course of rehabilitation (the 34th, given in October, 1988), a total of 420 professionals were trained over a period of 9 years.

\section{IMPLEMENTATION OF LOCAL PROGRAMMES}

The implementation of local programmes of rehabilitation was finalized in five Brazilian cities: Rio Branco AC, Manaus AM, Belem PA, Guarulhos SP and Porto Alegre RS.

The Rio Branco Programme is linked to the State Health Dermatology Service and involves the training of personnel for physiotherapy and surgery, and has generated a subprogramme in Cruzeiro do Sul. The surgical activities in Rio Branco are based on a general hospital of the Health Department and on a private general hospital (São Camilo Hospital). Modified shoes and prostheses are available from a workshop sponsored by a nongovernmental entity.

The Manaus Programme is based at the 'Alfredo da Mata' Outpatient Centre where prevention of incapacity and selection of cases are carried out. Surgery is performed at the 'Adriano Jorge' Hospital, linked to the Ministry of Health.

The Belem Program is located in the 'Demetrio Medrado' Centre for the Prevention and Treatment of Incapacities. The selection and preparation of cases is made in this Centre and surgery is performed in private general hospitals in the community.

The Guarulhos Program is located in the 'Padre Bento' Hospital of the State Health Department and receives professional rehabilitation support from a branch of SORRI in the same city.

The Porto Alegre Program is based at the Sanitary Dermatology Outpatient Centre of the State Health Department. Surgery is performed in general hospitals of the community and shoe modifications and prostheses are obtained from the National Health Insurance System. 
Thus, the main programmes are located exactly where prevalence of the disease is most significant and the activities are performed by local trained personnel using the resources of the community in addition to those provided by official institutions.

\section{Programme maintenance}

Thirty-six programme maintenance visits had been made up to December 1987 with the main objective of encouraging expansion by including additional personnel in the programme.

Table 1. Distribution of operations performed by one of the physicians in charge of the programme from 1982 to 1987

\begin{tabular}{|c|c|c|c|}
\hline Region & Surgery & Number & $\%$ \\
\hline \multirow{12}{*}{ Upper limbs } & Correction claw hand & 51 & $11 \cdot 35$ \\
\hline & Neurolyses & 30 & 6.68 \\
\hline & Correction of lack of & & \\
\hline & opposition of the thumb & 29 & $6 \cdot 45$ \\
\hline & Release of contractures & 24 & $5 \cdot 34$ \\
\hline & Interphalangeal arthrodeses & 16 & $3 \cdot 56$ \\
\hline & Others & 13 & $2 \cdot 89$ \\
\hline & Prosthesis for the first & & \\
\hline & web in the hand & 07 & $1 \cdot 55$ \\
\hline & Nerve biopsies & 03 & 0.66 \\
\hline & Skin biopsies & 03 & $0 \cdot 66$ \\
\hline & Tumour excision & 03 & 0.66 \\
\hline \multirow[t]{6}{*}{ Subtotal } & & 179 & $43 \cdot 80$ \\
\hline & Treatment of plantar ulcers & 51 & $11 \cdot 35$ \\
\hline & Treatment of leg ulcers & 35 & $7 \cdot 79$ \\
\hline & Correction of drop foot & 32 & $7 \cdot 12$ \\
\hline & Correction of clawed toes & 24 & $5 \cdot 34$ \\
\hline & Neurolyses & 12 & 2.67 \\
\hline \multirow[t]{5}{*}{ Lower limbs } & Toe arthrodeses & 10 & $2 \cdot 22$ \\
\hline & Nerve biopsies & 03 & 0.66 \\
\hline & Skin biopsies & 02 & 0.44 \\
\hline & Amputations & 02 & $0 \cdot 44$ \\
\hline & Others & 02 & 0.44 \\
\hline \multirow[t]{4}{*}{ Subtotal } & . & 173 & $38 \cdot 47$ \\
\hline & Nasal reconstruction & 22 & $4 \cdot 89$ \\
\hline & Correction of Lagophthalmus & 22 & $4 \cdot 89$ \\
\hline & Blepharoplasty & 15 & $3 \cdot 34$ \\
\hline \multirow[t]{5}{*}{ Face } & Correction of megalobule & 11 & $2 \cdot 44$ \\
\hline & Correction of madarosis & 08 & $1 \cdot 78$ \\
\hline & Excision of skin tumours & 05 & $1 \cdot 11$ \\
\hline & Tarsorrhaphies & 05 & $1 \cdot 11$ \\
\hline & Correction of ectropion & 05 & $1 \cdot 11$ \\
\hline \multirow[t]{2}{*}{ Subtotal } & & 93 & $20 \cdot 67$ \\
\hline & Correction of gynaecomastia & 04 & $0 \cdot 89$ \\
\hline Total & & 449 & \\
\hline
\end{tabular}


Table 2. Frequency and distribution of complications recorded during the evaluation of patients after operation for correction of lack of thumb opposition due to paralysis of the median nerve

\begin{tabular}{|c|c|c|c|}
\hline Complication & Number & $\begin{array}{c}\text { Cases with } \\
\text { complications }(\%)\end{array}$ & $\begin{array}{c}\text { Total number } \\
\text { of cases }(\%)\end{array}$ \\
\hline Infection & 1 & $11 \cdot 11$ & $3 \cdot 44$ \\
\hline Dehiscence of anastomosis & 1 & $11 \cdot 11$ & $3 \cdot 44$ \\
\hline Migration of the tendon* & 4 & $44 \cdot 44$ & $13 \cdot 79$ \\
\hline 'Check-rein' deformity $\dagger$ & 1 & $11 \cdot 11$ & $3 \cdot 44$ \\
\hline $\begin{array}{l}\text { Loss of flexion strength } \\
\text { in the forth finger }\end{array}$ & 2 & $22 \cdot 22$ & $6 \cdot 89$ \\
\hline
\end{tabular}

* This particular complication did not adversely affect the satisfactory results obtained for these patients.

$\dagger$ This is an adherence of the distal stump of the superficialis tendon which causes a flexion contraction of the proximal interphalangeal joint.

The surgical operations performed from 1982 to 1987 at the reference centre and at local programmes are listed in Table 1 (preliminary survey).

The evaluation of the specific results of surgery is beyond the scope of the present report. To illustrate, we will simply cite the evaluation of 29 cases of correction of loss of thumb opposition treated by the techniques of Bunnell-Brand. ${ }^{14}$ Results were satisfactory in $93 \cdot 10 \%$ of cases and unsatisfactory in $6.90 \%$, as evaluated by the criteria established by Palande. ${ }^{15}$ In general satisf actory results were those where the patients were able to abduct the thumb and make a pinch with the second finger in a manner adequate for routine activities. Results were considered unsatisfactory when one or more of the complications listed in Table 2 occurred.

\section{Discussion}

The data presented here led us to consider the priority that should be given to rehabilitation measures within a control programme. Indeed, several authors (e.g. Bechelli ${ }^{16}$ ) discuss the validity of rehabilitation of leprosy patients in countries with low budgetsf or control programmes. There is agreement that budget priorities should involve early diagnosis and adequate treatment, i.e. the measures that are the best to prevent deformities. However, there is sufficient evidence to show that physical rehabilitation should be included in the control of leprosy if we consider that:

1 The figures referring to deformities are highly significant. One study ${ }^{4}$ reported the presence of deformities in $35.85 \%$ of patients in Central and South America. Dinis (cited by Mallac ${ }^{17}$ ) reported a $25 \%$ figure for Brazil. Enna ${ }^{18}$ (1974) reported that $25 \%$ of registered cases required some type of surgical correction of deformity. Oberlin et al. ${ }^{19}$ reported that $10-15 \%$ of patients in any treatment group could benefit from physical rehabilitation and finally Duerksen, ${ }^{20}$ on the basis of data recently made available by the Ministry of Health of Paraguay, pointed out that $30-40 \%$ of patients with leprosy show deformities that could be corrected or relieved by physical rehabilitation.

2 For the patient, the major significance of the disease resides in the deformity. Specific medication obviously cannot achieve recuperation with respect to deformities already present and the meaning of 'cure' for the patient resides in the solution of his deformities and not in a negative reading of his smear. Thus, physical rehabilitation acts as a feedback element in the initial phases of the control programme, since many of the rehabilitation procedures require adequate clinical treatment and effective measures for prevention of disability. 
3 In Brazil, the rehabilitation programmes functioning jointly with control programmes receive support mainly from alternative sources, which means that official budgets could be devoted to care during the initial stages of the control programmes.

Thus, considering that a concrete ideology and practice of surgical rehabilitation of patients with leprosy already exists in Brazil, the next essential stepconcerns clinical evaluation procedures, to be carried out in a rigorous manner according to epidemiological methodology with the objective of facilitating sectorial decisions. Indeed, a project has been designed for a multicentre exploratory study of the Brazilian experience in surgical rehabilitation of leprosy patients. The specific objectives are:

1 To evaluate the magnitude of the demand for physical rehabilitation within the context of: (a) the local epidemiological structure of leprosy; and (b) the local structure of the network of health services.

2 To evaluate the impact of the physical rehabilitation procedures on the basis of the following indicators: (a) clinical evolution; (b) functional evolution; (c) professional evolution; and (d) social evolution.

3 To evaluate the efficiency of the physical rehabilitation procedures on the basis of health administration indicators such as concentration and direct and indirect costs.

The importance of surgical procedures in physical rehabilitation could be determined by the case-control method as follows: af ter the information referring to item 1 is obtained, each surgical patient would be paired with a similar patient matched for nosographic and observed and recorded physical conditions who: (a) was submitted to any physical rehabilitation procedure; (b) was submitted to a clinical procedure only; and (c) was submitted to both clinical and surgical procedures.

This would involve the following groups:

Group 1: diagnosed patients who had not completed 12 months of clinical treatment.

Group 2: diagnosed patients with at least 12 months of continuous clinical treatment.

Group 3: diagnosed patients with at least 12 months of clinical treatment and submitted to care for the prevention of disability with simple techniques for at least 6 months.

Group 4: patients as defined in group 3 and submitted to rehabilitation surgical procedures at least 12 months before.

\section{Conclusions and recommendations}

1 In Brazil, the number of leprosy cases is significant from a public health point of view.

2 This is a disease with a high frequency of physical and social sequelae.

3 Studies have revealed that up to $30-40 \%$ of registered patients have functional sequelae involving disabilities that could be corrected or relieved by physical rehabilitation.

4 The social stigma attached to the disease and the relative lack of information about it among physicians represent an obstacle in the effective fight against leprosy.

5 Control programmes should include physical rehabilitation of the patient not only because this represents the final link in the chain of action, but also because it has a feedback effect in terms of target efficiency.

6 At a time when both theoretical and practical competence is available in Brazil, we believe that the next step should be an epidemiological evaluation of the clinical and therapeutic procedures involved in the fight against leprosy. 


\section{References}

1 Gonçalves A. Aspectos epidemiológicos e controle da hanseníase no Brasil. Bol Of Sanit Panam, 1987; 102(3): 246-56.

2 Sansarricq M. Leprosy in the World Today. Lepr Rev, 1981; 52 Suppl. 1: 15-31.

3 WHO International classification of impairments, disabilities and handicaps. A manual of classification relating to the consequence of disease. World Health Organization, Geneve, 1980.

4 Bechelli LM. Assessement of the importance of reconstructive surgery in the control of leprosy from the public health point of view. Acta leprologica (ca) (nouvelle serie), 1971; 45: 5-29.

5 Gonçalves A. Incapacidade em Hanseniase: um estudo da realidade em nosso meio. Hansen Int, 1979; 4(1): 26-35.

6 OMS/Organizacion Pan-Americana da Saude. Manual para o Controle da Hanseniase. Washington, public cient, 1983; 436.

7 Virmond 1984.

8 Gillies, HD. Plastic surgery of the eyelids and conjunctival sac. Trans ophthalmol Soc, UK, 1935; 55-375.

9 Andersen JG. Surgical treatment of lagophthalmos in leprosy by the Gillies temporalis transfer. Brit J Plast Surg, 1961; 14: 330-45.

10 Zancolli EA. Correction de la Garra digital por paralisis intrinsica. La operacion del "lazo". Acta Ortop Latino Americana April 1974; 1(n.1): 65-72.

11 Bunnell S. Tendon transfer in the hand and forearm. American Academy of Orthopedic Surgeons Instructional Course Lecture, vol. 6. Ann Arbor, JW Edwards, 1949.

12 Ober FR. Tendon transplant in the lower extremity. New Eng J Med, 1933; 209: 52.

13 Taylor RG. The treatment of claw toes by multiple transfer of flexorinto extensor tendons. J Bone Joint Sur, 1951; 33-B: 539.

${ }^{14}$ Brand PW. Deformity in Leprosy. In Cochrane RG. Leprosy in theory and Practice, John Wright \& Ltd. 1964.

15 Palande DD. Opponensplasty in intrinsic-muscle paralysis of the thumb in leprosy. J Bone Jt Surg. 1975; 57-A: 489-93.

${ }_{16}$ Bechelli LM. Discussion à propos de la communication du Dr J Borit. Acta Leprologica (nouvelle serie), 1972; 48-9: 167-8.

17 Mallac MJ. Onset and pattern of deformity in leprosy. Lepr Rev, 1966; 37: 71-9.

18 Enna CD. The deformities in leprosy. In Mcdowell F, Enna CD. Surgical Rehabilitation in Leprosy, The William \& Wilkins Co. Baltimore, 1974.

19 Oberlin CM, Nebout M, Bourrel P. Mission temporaire de chirugie de la lépre. A propos de trois missions en Republique Centrafricaine ayant permis la realisation de 71 interventions reparatrices. Acta Leprologica (nouvelle serie), 1982; 86-7.

20 Duerksen F. The importance of reconstructive surgery in the rehabilitation of the Hansen's diseased patient. Transactions of the Seventh International Congress of Plastic and Reconstructive Surgery, Rio de Janeiro, May 20-5, 1979. Jorge Ely, (ed.) 